\title{
A Simple Flow Injection Spectrophotometric Procedure for the Determination of Diazepam in Pharmaceutical Formulation
}

\author{
S. LiaWruAngrath, ${ }^{* \dagger}$ Jirayu MaKChit, ${ }^{*}$ and B. LiaWruAngrath ${ }^{* *}$ \\ *Department of Chemistry, Faculty of Science, Chiang Mai University, Chiang Mai, Thailand \\ **Department of Pharmaceutical Chemistry, Faculty of Pharmacy, Chiang Mai University, Chiang Mai, Thailand
}

\begin{abstract}
A single-channel flow injection (FI) manifold with spectrophotometric detection has been designed and fabricated for diazepam determination. A $100 \mu \mathrm{l}$ sample and/or standard solution containing diazepam was injected into a flowing stream of $0.1 \mathrm{~mol} \mathrm{~L}^{-1}$ hydrochloric acid with the optimum flow rate of $6.8 \mathrm{~mL} \mathrm{~min}^{-1}$. As soon as the sample reached the detector, the FI signal as a peak was recorded at $360 \mathrm{~nm}$. The optimum conditions for $\mu \mathrm{g}$ amounts of diazepam were achieved. A linear calibration graph over the range of $2-110 \mathrm{mg} \mathrm{L}^{-1}$ diazepam was obtained with the regression equation $Y=0.2926 X+0.5896\left(r^{2}=0.9929\right)$. The method was very sensitive, since as little as $0.60 \mathrm{mg} \mathrm{L}^{-1}$ could be detected; very reproducible with an RSD of 3.3\% $(n=11)$; and very rapid with a sampling rate of $100 \mathrm{~h}^{-1}$. The limit of quantitation $(10 \sigma)$ was $2.0 \mathrm{mg} \mathrm{L}^{-1}$. The proposed FI procedure has been satisfactorily applied to the quantitation of diazepam in commercial pharmaceutical formulations. The obtained results were in excellent agreement with those obtained by the conventional spectrophotometric method, verified by the student $t$-test at the $95 \%$ confidence level.
\end{abstract}

(Received August 11, 2005; Accepted November 2, 2005)

\section{Introduction}

Diazepam is an important member of the group of 1,4benzodiazepine derivatives, which have found extensive use in current therapy. It is used for the symptomatic relief of tension and anxiety, acute alcohol withdrawal, adjunct therapy in skeletal muscle apasms and is preferred by many clinicians for the management of status epilepticus. ${ }^{1}$

Nowadays, diazepam is the drug of choice for the control of acute seizures. It is inexpensive, widely available in resourcepoor countries and effective when given by the intravenous or rectal routes. When such drugs are used singly, they appear to be relatively safe, but are of significant pharmacological importance when in the presence of other depressant drugs, such as barbiturates, narcotics and phenothinzines. ${ }^{2}$ The wide use of these drugs necessitates a rapid, reliable and sensitive method for their quantitation.

Numerous analytical techniques based on gas chromatography, ${ }^{3}$ high performance liquid chromatography, ${ }^{4,5}$ capillary electrophoresis, ${ }^{6} \quad$ TLC-densitometry, polarography, ${ }^{7}$ the electrochemical method ${ }^{8}$ and spectrophotometry ${ }^{9}$ have been developed for determining benzodiazepines in various sample matrices. For examples, Yu et al. ${ }^{10}$ described a second-order derivative spectrometric method for diazepam determination in commercial injection. Measurements were made at 343, 339, $335,323,319$ and $315 \mathrm{~nm}$. The mean recovery $(n=3)$ of diazepam was $100.3 \%$ with a coefficient of variation of $0.6 \%$.

A reversed-phase HPLC procedure with UV detection was reported for diazepam determination in plasma samples from children with severe malaria. ${ }^{11}$ Liu et al. ${ }^{12}$ described an RP-

\footnotetext{
† To whom correspondence should be addressed.

E-mail: scislwrn@chiangmai.ac.th
}

HPLC method for the quantitation of diazepam and its metabolites in dog plasma. A flow injection (FI) fluorometric determination of diazepam and other benzodiazepines in pharmaceutical preparations after hydrolysis was developed. ${ }^{13}$ Recently, a derivative UV spectrophotometric method has been proposed for the simultaneous determination of phenylpropanolamine hydrochloride, caffeine and diazepam in tablets. Satisfactory results were obtained and were in good agreement with those obtained by RP-HPLC. ${ }^{14}$ A thin-layer chromatographydensitometry technique has been developed for the separation and determination of diazepam and other benzodiazepine derivatives in tablets. ${ }^{15}$ TLC-densitometry, although the yield has slightly higher values than the HPLC method, is preferred, owing to its simplicity, ease and low-cost. Salem et al. ${ }^{16}$ described spectrophotometric and fluorometric methods for determining diazepam, bromazepam and clonazepam in pharmaceutical and urine samples. The methods are based on measuring the absorption or emission spectra in a methanolic potassium hydroxide solution. Fluorometric methods have proved to be selective with low detection limits $\left(7.13 \mathrm{ng} \mathrm{mL}^{-1}\right)$, whereas spectrophotometric methods show relatively high detection limits $\left(1.27 \mu \mathrm{g} \mathrm{ml}^{-1}\right.$ for diazepam).

However, many of such procedures have been criticized as being tedious, time consuming with occasionally suffer from lack of selectivity. Some modern analytical techniques are limited by the large sample volume extraction procedures of laboratories and long reaction times. Most instrumental methods are very expensive, which are not suitable for poor countries.

The present work describes a very simple, rapid, reliable and inexpensive FI method for diazepam determination. This method is very useful for the quality control of this drug production in industries, and is very suitable for developing countries. 


\section{Experimental}

\section{Instrumentation}

A single-channel flow injection (FI) manifold was designed using a UV-VIS spectrophotometer (Model SP6-400 spectrophotometer, Pye Uniscan, Co. Ltd.) as a detector. The absorbances were measured at $360 \mathrm{~nm}$ with the SP6-400 spectrophotometer equipped with a $30 \mu \mathrm{l}, 10 \mathrm{~mm}$ path-length optical quartz flow-through cell (Beckman). The FI gram was recorded with a servograph, Rec.51 chart recorder (radiometer Copenhagen). A reagent and/or carrier solution was introductced into the FI system by means of a laboratory-made peristaltic pump equipped with Tygon pump tubes. A sample and/or standard solution was injected into the FI system via a laboratory-made injection valve, and a coiled reactor was used for mixing. Tygon and PTFE tubings with $0.8 \mathrm{~mm}$ i.d. were used as flow lines.

\section{Materials}

Standard diazepam was purchased from Sigma (St. Louis, MO, USA). Hydrochloric acid was from Merck (Germany). Tablets and/or capsules of the drug were purchased from chemist shops in Chiang Mai Province, Thailand.

All of the tablets studied contained lactose, magnesium stearate and carboximethylcellulose sodium as excipients.

\section{Chemicals and reagents}

All chemicals were of analytical reagent grade and used without further purification. Deionized distilled water was used throughout.

A stock solution (1000 $\mathrm{mg} \mathrm{L}^{-1}$ ) of standard diazepam (Sigma, St. Louis, MO, USA) was prepared by dissolving $10 \mathrm{mg}$ of diazepam (accurately weighted) in $10 \mathrm{~mL}$ of ethanol. Working standard solutions of diazepam $\left(1-120 \mathrm{mg} \mathrm{L}^{-1}\right)$ were prepared by appropriate serial dilution of the stock solution.

Hydrochloric acid $\left(1 \mathrm{~mol} \mathrm{~L}^{-1}\right)$ was prepared by pipetting 24 $\mathrm{mL}$ of concentrated hydrochloric acid (Merck, Germany) in 250 $\mathrm{mL}$ of water. The solution was standardized with standard sodium hydroxide (previously standardized) using Bromothymol Blue as an indicator. Dilute hydrochloric acid solutions $\left(0.03-0.25 \mathrm{~mol} \mathrm{~L}^{-1}\right)$ were prepared by appropriate dilution of the $1 \mathrm{~mol} \mathrm{~L}^{-1}$ hydrochloric acid solutions.

\section{Sample preparation}

A total of 10 tablets were accurately weighed and finely powdered. A portion of the powder, equivalent to $1 \mathrm{mg}$ diazepam, was accurately weighed, transferred to a flask and suspended in $5 \mathrm{~mL}$ of ethanol. The flask was then placed in an ultrasonic water bath for 5 min and filtered through a Whatman No. 41 filter paper into a $10 \mathrm{~mL}$ volumetric flask and diluted to the volume with ethanol.

A total of 10 capsules containing $2 \mathrm{~g}$ of diazepam were taken. The drug was then removed from the capsules and weighed. The capsule contents were ground and mixed well. After fine powdering, an appropriate portion containing an equivalent of 1 $\mathrm{mg}$ of diazepam was accurately weighed, and dissolved in 25 $\mathrm{mL}$ of ethanol, followed by the procedure described above for tablets.

\section{Recommended procedure}

Using the fabricated FI manifold, the experimental conditions for determining diazepam were optimized by the univariate method. Under the optimum conditions, the recommended FI procedure was applied. After optimization of the experimental conditions, a $100 \mu \mathrm{l}$ sample solution was injected into a $0.1 \mathrm{~mol}$ $\mathrm{L}^{-1} \mathrm{HCl}$ stream at a constant flow rate of $6.8 \mathrm{ml} \mathrm{min}^{-1}$ via a home-made injection valve. When the sample plug reached the flow-through cell, the absorbance was detected at $360 \mathrm{~nm}$, which was recorded as a function of time. The peak height measured in $\mathrm{mV}$ was directly related to the diazepam concentration in the sample solution. After determining the drug contents in each sample solution by reference to a calibration graph prepared under identical conditions, the diazepam contents in both the tablets and capsules were then calculated.

\section{Results and Discussion}

Diazepam in a dilute $\mathrm{HCl}$ solution exhibits an absorption maximum at $360 \mathrm{~nm}$ with a reasonably large absorbance, which leads to a basis for the development of a simple FI procedure for diazepam determination. The large absorbance is due to protonated diazepam formed in the hydrochloric acid solution. This large absorbance arising from protonated diazepam in the UV region $\left(\lambda_{\max }\right.$ of $360 \mathrm{~nm}$ ) seems to be promising to improve the sensitivity for this drug determination in pharmaceutical formulations. However, in the UV region, there are many organic substances absorbing UV radiation, which can more or less interfere with the determination of the drug of interest. In the present work, the method of standard addition was used to overcome any matrix effects. The optimum experimental conditions for such drug assay were achieved using univariate methods, which were the wavelength, $360 \mathrm{~nm}$; the $\mathrm{HCl}$ concentration, $0.10 \mathrm{~mol} \mathrm{~L}^{-1}$; the $\mathrm{HCl}$ flow rate, $6.8 \mathrm{ml} \mathrm{min}^{-1}$; the mixing tubing diameter, $0.8 \mathrm{~mm}$ i.d.; the mixing tubing length, $70 \mathrm{~cm}$; the mixing coil diameter, $1.6 \mathrm{~cm}$; and the injection volume, $100 \mu \mathrm{L}$.

\section{Optimization of experimental conditions}

A preliminary investigation revealed that the use of a relatively low-cost spectrometer, (Spectronic 21, Bausch and Lomb) as the FI detector resulted in unsatisfactory results due to the poor reproducibility and sensitivity (slope of the calibration graph). Therefore, a more selective spectrophotometer, the UVVis spectrometer Model SP6-400 (Pye Unicom Co. Ltd., England), was in conjunction with the home-made FI system instead of the Spectronic 21. Satisfactory results were obtained.

In order to obtain a reliable, simple and rapid FI procedure for diazepam determination in pharmaceutical formulations for quality control in drug industries where these drugs are manufactured, it is necessary to investigate the optimum experimental parameters, as mentioned above.

The absorption spectrum of diazepam $\left(25 \mathrm{mg} \mathrm{L}^{-1}\right)$ in $0.1 \mathrm{~mol}$ $\mathrm{L}^{-1} \mathrm{HCl}$, obtained by the FI procedure under given conditions (loosely optimized rather quickly) revealed that the maximum absorption of such a drug ranges from 350 to $370 \mathrm{~nm}$, and that the absorbances measured in $\mathrm{mV}$ at 350,360 and $370 \mathrm{~nm}$ are $17.0,17.4$ and $16.5 \mathrm{mV}$, respectively. In order to achieve the greatest sensitivity, $360 \mathrm{~nm}$ was selected for subsequent experiments.

The effect of various hydrochloric acid concentrations (0.03$0.30 \mathrm{~mol} \mathrm{~L}^{-1}$ ) on the absorbance as peak height in $\mathrm{mV}$ arising from $25 \mathrm{mg} \mathrm{L}^{-1}$ diazepam was investigated. It is clear that at low $\mathrm{HCl}$ concentrations $\left(0.03\right.$ and $\left.0.05 \mathrm{~mol} \mathrm{~L}^{-1}\right)$ the absorbance increased very slightly, above which the absorbance increased very rapidly and reached the maximum absorption up to $0.1 \mathrm{~mol}$ $\mathrm{L}^{-1} \mathrm{HCl}$. The peak height remained constant when the $\mathrm{HCl}$ concentrations ranged from $0.10-0.20 \mathrm{~mol} \mathrm{~L}^{-1} \mathrm{HCl}$. For 
additional increments of the $\mathrm{HCl}$ concentration $\left(>0.20 \mathrm{~mol} \mathrm{~L}^{-1}\right)$, the absorbance decreased very rapidly. A $0.10 \mathrm{~mol} \mathrm{~L}^{-1} \mathrm{HCl}$ was chosen as an appropriate $\mathrm{HCl}$ concentration to minimized the $\mathrm{HCl}$ consumption. The $0.10 \mathrm{~mol} \mathrm{~L}^{-1} \mathrm{HCl}$ was sufficient to generate an appropriate amount of protonated diazepam for FIA measurements at $360 \mathrm{~nm}$. The reagent and/or carrier flow rate should be optimized to obtain a rapid method, minimal dispersion with maximal absorbing species, and hence, sensitivity.

The effect of a $0.1 \mathrm{~mol} \mathrm{~L}^{-1} \mathrm{HCl}$ stream on the peak height of $25 \mathrm{mg} \mathrm{L}^{-1}$ diazepam was examined by varying the $\mathrm{HCl}$ flow rates between 4.3 and $7.1 \mathrm{~mL} \mathrm{~min}^{-1}$. The peak height increased

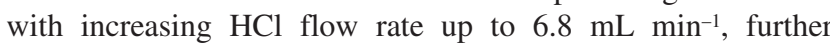
increases in the $\mathrm{HCl}$ flow rate resulted in depressing the peak height, whereas $t_{\text {base }}$ decreased with increasing $\mathrm{HCl}$ flow rate up to $6.6 \mathrm{~mL} \mathrm{~min}^{-1}$. It was evident that the lower was the $\mathrm{HCl}$ flow rate the longer was the residence time obtained, and that the higher was the $\mathrm{HCl}$ flow rate the shorter was the time required for each sample to reach through the FI system. However, a too high flow rate could lead to poor reproducibility and a large amount of reagent consumption, whereas a low flow rate could result in a large dispersion and time-consumption. With respect to the peak height, it was found that the maximum responses $(10.60 \mathrm{mV})$ was obtained at a $\mathrm{HCl}$ flow rate of $6.8 \mathrm{~mL} \mathrm{~min}^{-1}$ with a residence time of $36 \mathrm{~s}$. For a further increase in $\mathrm{HCl}$ flow rate the absorbance decreased and the resident time was the same $(36 \mathrm{~s})$ up to a flow rate of $8.0 \mathrm{~mL} \mathrm{~min}^{-1}$. Therefore, as a compromise between the sample throughput sensitivity and the reagent consumption, flow rate of $6.8 \mathrm{~mL} \mathrm{~min}{ }^{-1}$ was chosen as being the optimum.

\section{Effect of the size and length of the mixing tubing}

The mixing tubings used as flow lines and the mixing reactor play important roles on the FI signal because the peak signal depends on the resident time of the sample zone in tubing with an appropriate internal diameter and the length of the tubings used. The inner diameter of the mixing tubing has to be optimized, because the dispersion of samples zone increases with the mixing tubing diameter, and band broadening eventually results in a loss of sensitivity and a lower sampling rate. ${ }^{17}$ The reaction coil length should be optimized to ensure adequate dispersion and kinetics for absorbing species formation, so as to achieve the desired sensitivity. For these reasons, the internal diameter and the length of the tubing were altered over ranges of $0.5-1.3 \mathrm{~mm}$ i.d. and $30-100 \mathrm{~cm}$, respectively, for diazepam determination. It was found that the suitable internal diameter and length of the tubings employed in this work were $0.8 \mathrm{~mm}$ i.d. and $70 \mathrm{~cm}$, respectively, judging from the size and length of the tubing that exhibited the greatest peak signal.

A coiled reactor was made from Tygon tubing with an appropriate internal diameter and length (previously optimized) wound around a glass or plastic tube with various outer diameters. In order to obtain the greatest peak signal for diazepam determination, the mixing coil diameter (tube diameter) was optimized by varying the tube outer diameter over the range $1.0-3.0 \mathrm{~cm}$. It was revealed that a $1.6 \mathrm{~cm}$ o.d. tube, around which the Tygon tubing was wound, provided the greatest peak height with a reasonable residence time and reproducibility (less than $3 \%$ ). The coil diameter of the mixing tube should be optimized to obtain effective mixing of the reactants at the coiled reactor, where the chemical reaction occurs favorably, since the dispersion in open tubular reactors with various geometrics are different. ${ }^{18}$ The choice of the open tubular reactors geometrics for FI systems depends on the analytes of interest and the employed chemical reaction. ${ }^{19,20}$

It is necessary to optimize the injection volume to obtain the required sensitivity, because the amounts of sample injected into the FI system should be sufficient to permit effective reactions. Therefore, the effect of various injection volumes (50 $-200 \mu \mathrm{L}$ ) on the peak signal for diazepam determination was studied. A peak height of $25 \mathrm{mg} \mathrm{L}^{-1}$ diazepam increased with increasing the injection volume up to $100 \mu \mathrm{L}$. Upon further increases of the injection volume, the peak height decreased rather rapidly and reached the minimum signal when the injection volume increased up to $200 \mu \mathrm{L}$.

\section{Calibration graph, detection limit and limit of quantitation}

Under the optimum conditions, a linear calibration graph over the range of $2.00-110.0 \mathrm{mg} \mathrm{L}^{-1}$ was established with the linear regression equation $Y=0.2926 x+0.5896\left(r^{2}=0.99291\right)$. When the drug concentration exceeded $110.0 \mathrm{mg} \mathrm{L}^{-1}$, the absorbance began to decrease, and a deviation from Beer's Law was observed. The detection limit $(3 \sigma)$ and the limit of quantitation $(10 \sigma)$ were found to be 0.6 and $2.0 \mathrm{mg} \mathrm{L}^{-1}$, respectively.

\section{Reproducibility and accuracy}

The proposed FI method was very reproducible, permitting the determination of $25 \mathrm{mg} \mathrm{L}^{-1}$ with an RSD of $3.3 \%$. The accuracy of the method was determined by 7 replicate injections of $100 \mu \mathrm{L}$ of a commercial drug sample solution both unspiked and spiked with the drug being studied. The mean recovery was found to be $102.6 \pm 3.1 \%(n=7)$, indicating that the proposed procedure was very accurate.

\section{Interferences}

Some possible common excipients that might be present in these drug formulations were investigated. It was clear that all of the common excipients studied exhibited no effect on diazepam determination, even through they were present up to 10 - 50 times the weight ratio to diazepam.

\section{Application}

The proposed FI method has been satisfactorily applied to the determination of diazepam in commercial pharmaceutical preparations after appropriate sample pretreatments with a sample throughput of $100 \mathrm{~h}^{-1}$. Matrix effects could be eliminated using the method of standard addition. A comparative determination of diazepam in the same sample solutions by spectrophotometry using the standard addition method was also carried out. The results obtained from both methods were in excellent agreement, evaluated by the student $t$-test at the $95 \%$ confidence level. The $t$ value calculated from the experimental results was 0.43 , which is far more less than that from the $t$-Table, indicating that there were no significant differences between the results obtained by both methods. The percentage labeled amounts obtained by the proposed FI procedure were in the ranges of $99.0-101.0$ and $99.8-101$ for capsules and tablets, respectively. However, those obtained by batch-wise spectrophotometric methods were 98.5-100 and 101.5 - 102.4 for capsules and tablets, respectively.

\section{Conclusion}

The recommended FI procedure for diazepam determination has proven to be very simple, rapid, reproducible and accurate, and also fairly sensitive and selective using the method of standard addition to compensate for any matrix effects. The method was satisfactorily applied to the determination of diazepam in five 
commercial pharmaceutical formulations with a sampling rate of $100 \mathrm{~h}^{-1}$. The method is therefore suitable for quality control in drug industries where benzodiazepines are manufactured, especially in poor countries. The purposed FI method may be applicable to the analysis of diazepam only in pharmaceutical formulations. Regarding other sample matrices, derivative spectrometry is more suitable, since it is capable of eliminating spectral background interferences and increasing the resolution of any overlapped signal. ${ }^{21}$

\section{Acknowledgements}

The authors would like to express their sincere thanks and appreciation to the Postgraduate Education and Research Program in Chemistry (PERCH) and the Graduate School of Chiang Mai University for their partial support. Thanks are also expressed to the Department of Chemistry, Faculty of Science, Chiang Mai University for providing the equipment and all laboratory facilities.

\section{References}

1. J. Bruhwyler and A. Hassoun, J. Anal. Toxicol., 1992, 16, 244.

2. B. Pypendop, D. Serteyn, and J. Verstegen, Am. J. Vet. Res., 1996, 57, 724.

3. M. Krogh, H. Grefslie, and K. E. Rasmussen, $J$. Chromatogr., B, 1997, 689, 357.

4. J. H. Nichols, J. R. Charlson, and G. M. Lawson, Clin. Chem., 1994, 40, 1312.

5. C. F. Ferreyra and C. S. Ortiz, J. Pharm. Biomed. Anal., 2001, 25, 493.
6. W. F. Smyth and S. Mcclean, Electrophoresis, 1998, 19, 2870.

7. C. Sarbu and G. Cimpan, J. Planar Chromatogr.-Mod. $T L C$, 1996, 9, 126.

8. W. F. Smyth and A. Ivaska, Analyst, 1985, 110, 1377.

9. A. A. Salem, B. N. Barsoum, and E. T. Ezake, Anal. Lett., 2002, 1631, 35.

10. S. Yu and B. Zeng, Yiyao Gongye, 1988, 19, 331.

11. S. N. Muchohi, B. R. Ogutu, C. P. J. C. Newton, and S. O. Kokware, J. Chromatogr., B: Biomed. Appl., 2001, 761, 255.

12. Z. Liu, J. Short, A. Rose, S. Ren, N. Contel, S. Grossman, and S. Unger, J. Pharm. Biomed. Anal., 2001, 26, 321.

13. J. Dolejsova, P. Solich, C. K. Polydorou, M. A. Koupparis, and C. E. Efstathiou, J. Pharm. Biomed. Anal., 1999, 20, 357.

14. C. F. Ferreyra and C. S. Ortiz, J. Pharm. Biomed. Anal., 2002, 29, 811.

15. M. Bakavolli and M. Kaykhaii, J. Pharm. Biomed. Anal., 2003, 31, 1185.

16. A. A. Salem, B. N. Barsoum, and E. L. Izake, Spectrochim. Acta, A, 2004, 60, 771.

17. J. Ruzicka and E. H. Hansen, "Flow Injection Analysis", 2nd ed., 1988, Wiley, New York.

18. P. K. Dasgupta and D. K. Wolcott, Anal. Chim. Acta, 2001, 428, 163.

19. B. Purachat, S. Liawruangrath, P. Sooksamiti, S. Rattanaphani, and D. Buddhasukh, Anal. Sci., 2001, 17, 443.

20. S. Liawruangrath and S. Sakulkhaemaruethai, Talanta, 2003, 59, 9 .

21. K. Kitamura, N. Inayoshi, T, Goto, H. Shiro, T. Mamo, and Y. Nakai, Anal. Chim. Acta, 1995, 304, 101. 